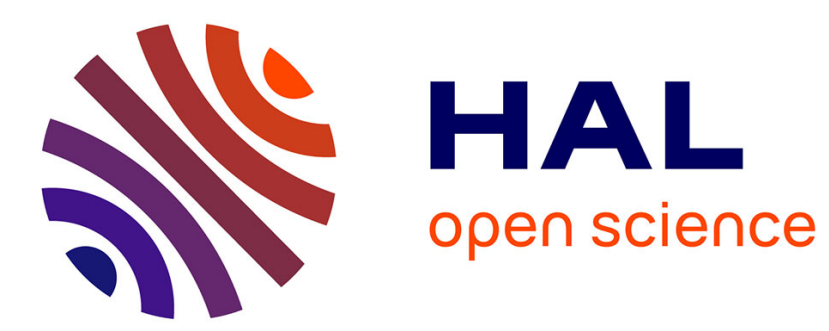

\title{
Forest Owners Motivations for Adopting Programs of Biodiversity Protection \\ Philippe Polomé
}

\section{To cite this version:}

Philippe Polomé. Forest Owners Motivations for Adopting Programs of Biodiversity Protection. 2016. halshs-01323475

\author{
HAL Id: halshs-01323475 \\ https://shs.hal.science/halshs-01323475 \\ Preprint submitted on 30 May 2016
}

HAL is a multi-disciplinary open access archive for the deposit and dissemination of scientific research documents, whether they are published or not. The documents may come from teaching and research institutions in France or abroad, or from public or private research centers.
L'archive ouverte pluridisciplinaire HAL, est destinée au dépôt et à la diffusion de documents scientifiques de niveau recherche, publiés ou non, émanant des établissements d'enseignement et de recherche français ou étrangers, des laboratoires publics ou privés. 
UMR 5824

$$
\begin{array}{r}
\text { 93, chemin des Mouilles } \\
69130 \text { Ecully - France } \\
\text { Maison de r'Universite, Battiment B } \\
\text { 10, rue Trefilerie } \\
42023 \text { Saint-Etienne cedex 02 - France } \\
\text { http://www.gate.cnrs.fr } \\
\text { gate@gate.cnrs.fr }
\end{array}
$$

WP 1619 - May 2016

\title{
Forest Owners Motivations for Adopting Programs of Biodiversity Protection
}

Philippe Polomé

\begin{abstract}
:
The results of a survey of private forest owners on adoption of a number of current programs, that include biodiversity protection to some degree, are presented. Adoption amounts to $22 \%$ for all the programs jointly, and is shown to depend on economic, social and ethical motives, with significant crowding-out between the economic and ethical motives, but not with social motives. Adoption of each program is strongly negatively correlated to each other. Nearly no respondent adopted the Natura 2000 program.

The results constitute a test of the "reputational crowding-out" theory of Bénabou and Tirole (2006)
\end{abstract}

Keywords:

Non-indutrial private forest owner, biodiversity program, motivation crowding-out, adoption decision

JEL codes:

C64, H41, Q23, Q28, Z13

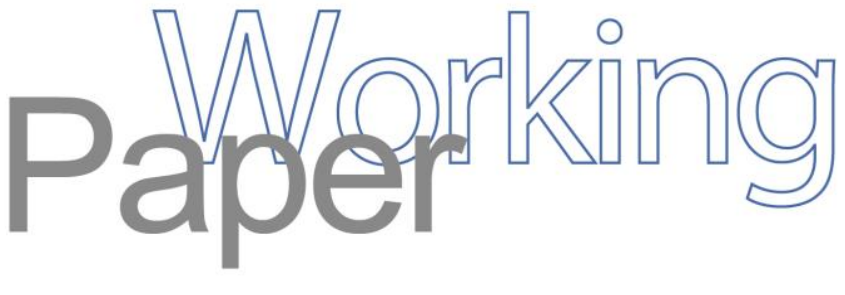




\title{
Forest Owners Motivations for Adopting Programs of Biodiversity Protection
}

\author{
Philippe Polomé
}

May. 2016

Univ Lyon, Université Lyon 2, CNRS, GATE UMR 5824, F-69130, ECULLY, France. polome@ gate.cnrs.fr

\begin{abstract}
The results of a survey of private forest owners on adoption of a number of current programs, that include biodiversity protection to some degree, are presented. Adoption amounts to $22 \%$ for all the programs jointly, and is shown to depend on economic, social and ethical motives, with significant crowding-out between the economic and ethical motives, but not with social motives. Adoption of each program is strongly negatively correlated to each other. Nearly no respondent adopted the Natura 2000 program.

The results constitute a test of the "reputational crowding-out" theory of Bénabou and Tirole (2006) [1].
\end{abstract}

Keywords. Non-indutrial private forest owner, biodiversity program, motivation crowding-out, adoption decision

JEL Codes. D64 Altruism • Philanthropy, H41 Public Goods, Q23 Forestry, Q28 Government Forestry Policy, Z13 Economic Sociology

Financial support from the research program "Biodiversité, gestion forestière et politiques publiques" of the "Ecosystèmes Forestiers" Public Interest Group (http://www.gip-ecofor.org/) and from the "Ministère de l'Environnement, de l'Energie et de la Mer - MEDDE" are gratefully acknowledged. The author wishes to thank F. Bigot de Morogues, J. Abildtrup, M. Blondet, A. Bouvet, C. Michel and A. Stenger for their helpful comments. All opinions and remaining errors are the author's. 


\section{Introduction}

This paper focuses on measuring the role of non-industrial private forest owners' motivations in adopting programs of biodiversity protection in France. There are a number of public voluntary programs that include biodiversity protection to some extent, even though they have other objectives as well. These include wood products sustainable forest management certification (PEFC-FSC), several types of forest management plans and the famous Natura 2000 program in which owners voluntarily commit to specific norms of forest management. Forest owners can also take part in non-public voluntary programs of forest management with varying degrees of biodiversity protection. These include various professional organizations such as cooperatives and syndicates (unions), environmental NGOs and the "ProSilva" organization promoting an alternative form of forest management.

Generally, behaviors of biodiversity protection may be termed prosocial in the sense that their social benefits exceed those of the supplier of the protection, or have a positive effect on society. Adoption of prosocial behaviors has been shown to depend more on social motives than on economic ones; for example, Freeman (1996) [8] shows that having been asked by a person is a more powerful motive than the economic one. Oliver (2013) [14] reviewed a number of applications of nudges that illustrate the importance, for designing public policy, of understanding the motives of adoption of such programs.

Self-determination theory, developed by psychologists Ryan and Deci (e.g. [15]) is a general theory that argues that individual may have extrinsic and intrinsic motivations. Extrinsic ones lead to what is termed "controlled" actions, that is, actions motivated by a pressure that is perceived as external to the individual, and can be more or less accepted ("integrated") by that individual. Such pressures are akin to penalties or rewards and encompass economic or financial incentives (penalties or rewards) to include threats, peer pressures and feelings of moral obligation. Intrinsic motivations, on the other hand, lead to actions that are called "autonomous", in the sense that the individual carries them out for themselves, without any perceived external pressure. The satisfaction (or utility) of an action is deemed higher when it is motivated intrinsically than by an extrinsic motivation. Thus, for a forest owner, adopting any particular program may be motivated extrinsically (e.g. because of financial incentives or because she thinks that it would be illegal not to adopt or because she is asked to adopt by a friend) or intrinsically because she identifies with this particular program. The diversity of motives in silvicultural and harvesting behaviors is well documented for non-industrial private forest owners, e.g. Karpinnen (1998) [11] or Kendra (2005) [12]. 
The present paper focuses on the formalization of prosocial behaviors, developed by Bénabou and Tirole (2005) [2] and (2006) [1]. These authors have a particular interest in economic (extrinsic) motives that they differentiate not only from the intrinsic motives (that they term public good and altruism) but also from the more social motives, with interpretations that include social network and self-image. ${ }^{1}$ In the present paper, economic motives (some of the extrinsic motives) include financial compensations or penalties; fiscal exemptions; risk hedging; time saving; acquiring management information; future or putative use. For many forest owners in the population of interest, the forest property is relatively small and forest income are negligible (Table (3)); economic motives might then not be very powerful and the other types of motives might be relatively important. Social motives (the rest of the extrinsic motives) include reputation (networks, family, peer-pressure); self-image (moral satisfaction, warm glow); desire to belong to a group or differentiate from it; socialization; reciprocity.

Ethical (the intrinsic motives) include the willingness to work for quality of the environment; well-being of the community; bequest or patrimony values; attachment to the forest. Bénabou and Tirole (2005, p.8) [2] refers to the intrinsic motives as "altruism and public goods". However, these concepts are interpreted in very different ways by different forests owners, as became apparent in stakeholders discussions and questionnaire tests. For example, Bénabou and Tirole (2005) [2] state on p.8 that the agent “... may care about the overall level of a public good...”. Such overall level is confusing when addressing forest owners as there is not a single dimension of the forest. Some owners will consider that the level is wood production, others that it relates more to a closerto-nature state of the forest, while still others see any reference to a non-private level as a form of intrusion into what they see as their sovereign property. For these reasons, intrinsic motives have been termed "ethical" here. Depending on the program under consideration, they include notions of attachment (to the forest) or of mastery (over forest practices), the environmental quality of the forest, or definite ideas on how a forest should be managed.

In some cases, the difference between social and ethical motives may appear thin, e.g. moral satisfaction and altruism, to name a case. The difference resides in the notion of extrinsic vs. intrinsic motivation following selfdetermination theory, that is, whether the adoption is "controlled" (motivated by a pressure perceived as external to the individual) or "autonomous" (the individual chooses the adoption "for itself"). That corresponds to the difference between the "moral satisfaction" and "public good and altruism" in Bénabou and Tirole (2006) [1], although, ultimately, the difference is one of degrees rather than a well-defined border. Indeed, self-determination

\footnotetext{
${ }^{1}$ Bénabou and Tirole (2005) [2] use the term "reputational" for these motives, e.g. p.3. For a more neutral interpretation, the present paper uses the term "social" instead.
} 
theory argues that any motivation for any particular action can be gradually internalized ("appropriated"), that is, the motivation can become more intrinsic as the individual identifies more with it.

These three categories of motives may act positively or negatively for any program, depending on the forest owner, e.g. economic incentive may be considered attractive for one, thus be declared as a motive for adopting a program; while it may be insufficient for another, and thus be cited for non-adoption of a program. Bénabou and Tirole (2006) [1] formalize the idea that the two kinds of extrinsic motivations - economic and social may be opposed and that everyone prefers that her actions (adoptions of programs in the present case) appear intrinsically motivated. Consequently, when a program becomes financially compensated, some of the adopters of this program might be concerned that their social network believes they adopt the program out of their interest for the money. While if it had not been financially incentivized, it would have been clear that they were adopting for intrinsic reasons. This "social credit" could then lead to an improved social image or better social networks. Whether this desire for improved social image is in turn motivated economically (e.g. accessing better prices through a network) or by other motives, is beyond the scope of the present paper.

Such crowding-out of the economic motives on the social ones reduces adoption for a range of (possibly small) economic incentives. This is one of the key ideas in Bénabou and Tirole (2006) [1], but similar crowding-out effects are abundantly documented, see e.g. Frey and Oberholzer-Gee (1997) [9], Gneezy and Rustichini (2000) [10], Nyborg and Rege (2003) [13], or Oliver (2013) [14]. From a public policy viewpoint, the existence of crowding-out questions the efficiency of the policy, particularly for environmental policies, since it means that economic incentives are sometimes wasted as they reduce adoption (or have a lower-than-expected effect) because they crowd-out social motivation. In Bénabou and Tirole, crowding-out can only occur when individuals are socially motivated; if they are only motivated intrinsically, then there is no ground for a crowding-out. But if it can be shown that forest owners' adoptions are (at least in part) socially motivated, then it may be the case that public policy should focus more on social reward of a policy than on economic reward.

Bénabou and Tirole (2006) [1] state that visibility of the economic motives is essential: if the economic incentive (reward or penalty) is not visible to a third party, then economic motives cannot be inferred from the forest owner's actions, and therefore, there is not crowding-out. In the present forestry case, economic incentives are fairly visible for some programs, because they correspond to legal aspects (e.g. fiscal deductibility of management plans), or because they are associated to a label (certifications) that presumably allows the owners to sell at a higher price. Some other programs do not have an explicit economic return, e.g. adhesion to the ProSilva association or adoption of Natura 2000 practices; or even may apparently lack any economic incentive, 
e.g. in the case of adhesion to an environmental NGO. Ultimately, visibility is a perception; it is very difficult to assess whether all forest owners have the same beliefs on the economic return of any program.

The main focus of the present paper is to test whether the Bénabou and Tirole construct might apply to a sample of forest owners, and to test whether crowding-out effects are already at work with the current biodiversity programs. It also to identify potential pitfalls and leverages of forest biodiversity policies. The paper is organized as follows. Section 2 presents the cross-section sample of forest owners in a French Regional Natural Park, then details the programs that these owners can choose to adopt, the motives that have been revealed in the survey and finally a socio-economic descriptions of the forest owners, of their properties, and of the spatial relationships between them. Section 3 presents the Bénabou and Tirole model formally, then interprets it in term of the econometric analysis of the adoption decisions and finally presents the econometric results. Section 4 concludes.

\section{Survey and Data Description}

\subsection{Sample}

The survey was administered during the first quarter of 2015 on the nearly 50000 non-industrial private forest owners of the Parc Naturel Régional des Ballons des Vosges (PNR), ${ }^{2}$ using the quotas method, by telephone following a prior letter that the respondents had received a few days earlier. The letter summarized the programs of interest, presented in the next section.

Table (1) shows that a large majority of forest owners have tiny, less than one ha, properties, as is quite typical in many French regions. Because there was an interest in these small owners, the minimal size of the property to qualify for the sample was set at 0.05 ha $\left(500 \mathrm{~m}^{2}\right)$, reaching a compromise between representativity in terms of property sizes and number of owners. Further, the 4 ha point is relevant as it is the minimum for fiscal exemption of forest management expenses or investments. The 10 ha point is the minimum to adopt a "Simple Management Plan" described in the next section. The resulting sample has four classes of about 130 respondents each, but for the fifth class, the properties of more than 10 ha, it was deemed that a sample of about 100 was the best that could be achieved. The final sample size was 627 . The sample was established on the basis of the properties in

\footnotetext{
${ }^{2}$ Regional natural area in the North-East of France.
} 
the cadastre of the PNR, but some owners also had properties elsewhere, or has sold some properties recently, explaining the differences between cadastre and stated surfaces.

Table 1: Surface (S) and owners classes

\begin{tabular}{|c|c|c|c|c|c|c|c|}
\hline \multirow{3}{*}{ वे } & Surface (ha) & $<1$ & $1<\mathrm{S}<4$ & $4<S<10$ & $10<S<25$ & $25<$ & Sum \\
\hline & Forest area (ha) & 10675 & 16364 & 10908 & 7499 & 15651 & 61097 \\
\hline & Owners (\#) & 38486 & 8580 & 1828 & 505 & 185 & 49584 \\
\hline \multirow{4}{*}{ 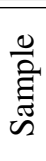 } & Surface (ha) & $.05-.74$ & $.75-1.99$ & $2-3.99$ & $4-9.99$ & $>10$ & \\
\hline & Planned (\#) & 128 & 128 & 128 & 128 & 90 & 600 \\
\hline & In cadastre PNR (\#) & 136 & 132 & 131 & 129 & 88 & 627 \\
\hline & Stated (\#) - 60 miss & 109 & 157 & 114 & 102 & 74 & \\
\hline
\end{tabular}

\subsection{Programs}

In the survey, private forest owners were asked about whether they had adopted each of the following programs. ${ }^{3}$ These programs are a grouping of several, possibly exclusive, programs, that are documented on the "forest owners portal" http://www.foretpriveefrancaise.com/les-services-aux-adherents-27775.html, the "directory of the private forest" http://www.foretpriveefrancaise.com/annuaire and in Weiss (2003) [17]. They were established with groups of stakeholders, bearing in mind that interview length must be kept short (about 20 minutes) and that the introduction letter had to be small (1 page).

These programs constitute the owner's choice set, that is all the possible forest-related programs feasible in the area of the PNR. This choice set may or may not be completely known by all the owners. Owners may certainly participate in other social or environmental actions, but the following list is bound together by the forest property and by the fact that the programs are in some ways competing for the owner's resources, in particular time. The programs are the following.

- Any (wood) certifications of sustainable management: PEFC, FSC,...

- Any forest management plan. These are good practices plans, that are intended for sustainable forest management. There are three plans, with different charters, that are directed to different types of forest owners or property. The "Simple Management Plan" (Plan simple de gestion) may be adopted when property size reaches 10 ha and becomes mandatory when it reaches 25 ha. The "Good Forest Practices Code" (Code des bonnes pratiques sylvicoles) is directed towards smaller properties. The "Standard

\footnotetext{
${ }^{3}$ As indicated, the owners had previously received the list of programs by post, on which each program was briefly summarized.
} 
Management Rule" (Règlement type de gestion) is directed to forests owners who own less than 25ha, and for whom the property is managed by a third party (expert or organization).

- Any forest owners management-related organization, e.g. cooperative (common management of their stakeholders' plots) or union (represent, inform and advice their members, can enter a "Simple Management Plan" on behalf of their members, may have environmental goals, or may be constituted only for very specific tasks). 37 such structures are available for owners of the PNR, and several forms of owners associations outside of these structures exist. They have a strong social component following Darses, Garcia, and Stenger (2011) [6] and Weiss (2003) [17].

- Pro Silva (French branch, "Association Futaie Irrégulière" - AFI) association of forest owners promoting a continuous and irregular form of management, closer to a natural cover.

- Natura 2000 are sites; for properties that belong to these sites, management must be submitted to impact assessment or the owner may choose to adopt the Natura 2000 charter. The owner may further commit through a Natura 2000 contract, which is more demanding than the charter.

- Any NGO for the defense of the environment (WWF, "France-Nature-Environnement"...) that presumably has bearing on forest management practices.

That amounts to seven programs since Natura 2000 is actually two programs : Charter and Contract. The survey showed several striking facts, some of which where unexpected. First, relatively few respondents, $22 \%$, participate in any program. Second, very few respondents ( 2 out of 627) participate in more than one program. ${ }^{4}$ Third, on 627 observations, there is only one adoption of the Natura 2000 charter and two adoptions of the Natura 2000 contract; these response rates have led to dropping these observations altogether. Consequently, the Natura 2000 program cannot be examined other than through understanding the motives of non-adoption. Fourth, few respondents adopted a certification, a management plan or a management organization; since these programs may be perceived as complements, they have been grouped into one, called "conventional management" for want of a better name as in the sample region, the "ProSilva" management is possibly more conventional than the other practices. These results led to redefine three "programs": ProSilva, Conventional management, Environmental NGO. The figures for adoption are presented in Figure (1) below.

\footnotetext{
${ }^{4}$ Regarding the econometric model presented in the sequel, this means that adoption of a program cannot be used as a regressor for estimating the probability of adopting another program as that would lead to a complete determination, that is $100 \%$ of those who adopt a program do not adopt another. Furthermore, the use of such regressor would lead to endogeneity issues since both adoptions would be correlated.
} 


\subsection{Motives}

For each of those programs, when a respondent answered that she adopted it, she was queried on her motives. Table (2) presents all the motives that have been invoked for adopting or not a certain program. Some motives are not relevant for some programs. The motives proceed from several meetings with stakeholders, but, for each program, there was the possibility for each respondent to state one or several other motives. Those were recorded, but were all anecdotical, that is, did not occur more than twice over the whole survey. Respondents also could always answer that they did not know or could also refuse to answer - though they were not prompted for such answers.

Apart from the Economic-Social-Ethical motives, there can be more circumstantial motives that respondents sometimes evoke. These are linked to a lack of information, e.g. the respondent was not aware of the program, or those who adopted out of curiosity. More generally, in contexts other than those of the forest owners in the present sample, there could be more technical motives - e.g. one could not adopt a Natura 2000 charter if her forest was not in a Natura 2000 forest. Such technical motives were not evoked by the respondents of the present survey. Finally, some respondents inevitably answer that they do not know their motivations of adoption, or that they have none.

Table 2: Detailed motives and grouping

\begin{tabular}{|c|c|c|}
\hline & Adoption & Non-adoption \\
\hline 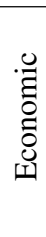 & $\begin{array}{c}\text { economic interest } \\
\text { time savings } \\
\text { fiscal advantages } \\
\text { compensation for game damages } \\
\text { insurances } \\
\text { owner believes program is legally mandatory }\end{array}$ & $\begin{array}{c}\text { lack of economic interest } \\
\text { time consuming } \\
\text { too complicated } \\
\text { commitments are too long or uncertain } \\
\text { owner's practices already include the program } \\
\text { owner believes program is not legal in his/her case }\end{array}$ \\
\hline $\begin{array}{l}\bar{\pi} \\
0 \\
0 \\
0\end{array}$ & $\begin{array}{l}\text { recommended by a friend/family/colleague... } \\
\text { do as the other owners } \\
\text { make an example } \\
\text { desire to enter a professional network }\end{array}$ & $\begin{array}{c}\text { lack of commitment of the other owners } \\
\text { the program does not have social recognition } \\
\text { lack of dialogue with forest owners on this program }\end{array}$ \\
\hline 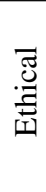 & $\begin{array}{l}\text { attachment to his/her forest } \\
\text { desire to bequest a better forest } \\
\text { improving the woods } \\
\text { personal belief } \\
\text { protect certain species }\end{array}$ & $\begin{array}{l}\text { (retaining mastery of practices) } \\
\text { respondent wishes no intervention in his practices } \\
\text { program is incompatible w/ owner's ecolog. or manag. actions } \\
\text { control by administration is too uncertain or complicated }\end{array}$ \\
\hline$\stackrel{\dot{0}}{\Xi}$ & $\begin{array}{c}\text { information need (technical, manag...) } \\
\text { curiosity }\end{array}$ & lack of information on the program \\
\hline
\end{tabular}

Following Table 2, respondents may have from zero to four motives to adopt a program, but also zero to four 
motives not to adopt a program. In the econometric model of the next section, each motive is modeled by a dichotomous variable, that is defined for each respondent. When a respondent does not reveal any of the four motives (economic, ethical, social, information), the value of these four dichotomous variables are set to zero. To assign a value to each of these dichotomous variables, each respondent could be asked to state the motive for adopting or not a particular program. However, at the conception phase of the questionnaire, it was quickly realized that it would be very tedious, and certainly unreliable, to ask respondents why they would not adopt a particular program. Instead, respondents were asked whether they adopted any of the programs, and in case they would answer negatively (no program was adopted - 78\% of the respondents), they were queried for the motives for not adopting. Similarly, respondents, who answered that they adopted some program(s), were asked to state the motives for not adopting any of the other programs in a single question, not program by program.

For each of the three previously defined programs - ProSilva, Conventional management, Environmental NGO these questions provide data on motives for those who adopted, but also for those who did not (whether they did not adopt any program, or they adopted another). In the very few instances in which a respondent has adopted more than a program, these motives have been merged.

Consequently, the motives for not-adopting are not the mirror image of the motives for adopting. The following figure reflects the different motives for the each program, and for not adopting any program. The large number of respondents who did not adopt any program led to a separate analysis.

Figure 1: Motivations by Program $-n=627$

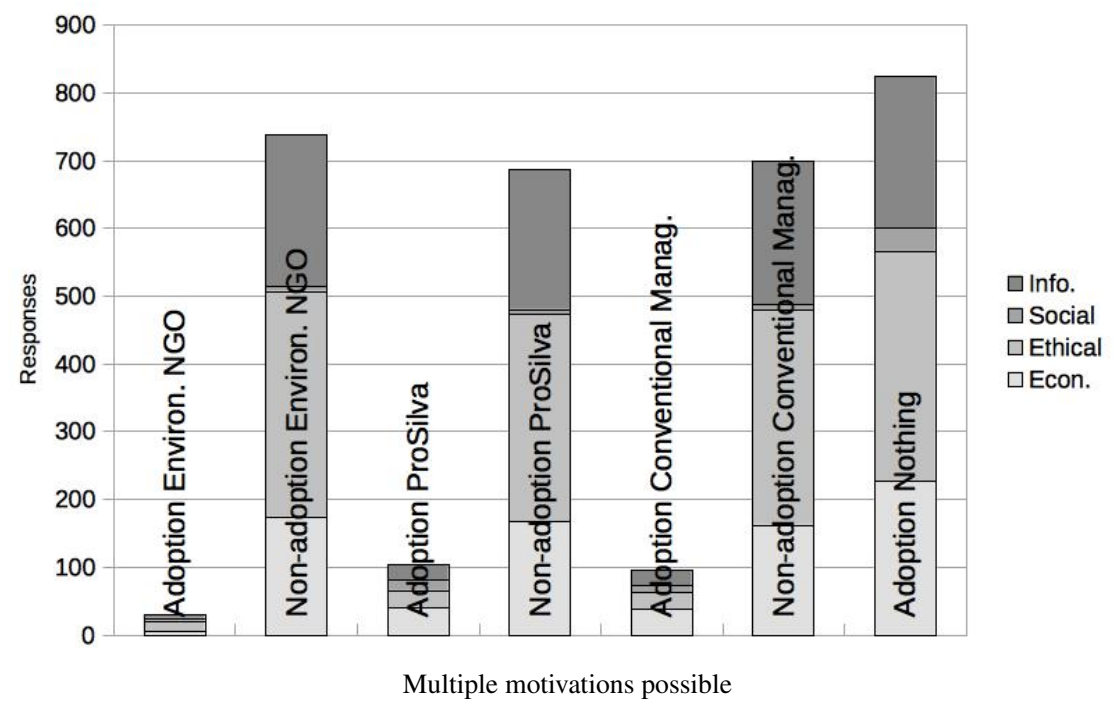


This process of construction of the motives data safeguards against a possible endogeneity of motives in the adoption decision, that would occur if only the motives for adopting were recorded.

The intensity of participation in the program could also be used to test crowding-out effect. Carpenter-Myers (2010) [5] found that intensity did not follow the same determinants as adoption. Intensity could be captured in the part of the property that is allocated to a program, for those programs for which that is meaningful, in the complexity of the program, and also in the length of time of the commitment. Regarding the former two, it was conjectured that such information would be too unreliable to be useful. The length of the commitment is captured in the questionnaire. Respondents who stated that they adopted a program were queried upon the date of adoption and whether the program was still followed. In case it was not, the person was asked the motive for abandonment. These are identical to the motives for not adopting. Since only four respondents rescinded adoption, this measure of intensity does not appear usable in the present sample.

\subsection{Exogenous Variables}

The owner's characteristics and the property characteristics that are susceptible to play a significant role in the probability of adopting a program were collected in the survey according to e.g. Delacote, Garcia, Stenger (2014) [7]. The more salient traits of the sample are described in Table (3). The questionnaire allowed for the collection of some spatial and social characteristics, i.e. whether the owner lives in the same postal code as the oldest parcel of her property (presumably of highest attachment), whether the owner knows the neighboring woods and/or their owners.

Table 3: Descriptive statistics of the owners and the properties - 627 observations

\begin{tabular}{|l|c|}
\hline Owner & Prop. \\
\hline Man & $81 \%$ \\
\hline Aged 66+ & $59 \%$ \\
\hline Completed high school & $34 \%$ \\
\hline In non-professional association & $29 \%$ \\
\hline Visits property at least 1/year & $70 \%$ \\
\hline Lives close to oldest parcel & $50 \%$ \\
\hline Has own environmental actions & $14 \%$ \\
\hline Hunts & $8 \%$ \\
\hline Knowns neighboring properties & $73 \%$ \\
\hline Forest income negligible & $88 \%$ \\
\hline Will bequest forest & $76 \%$ \\
\hline
\end{tabular}

\begin{tabular}{|l|c|}
\hline Forest (owner's opinion) & Prop. \\
\hline Last intervention before 2010 & $48 \%$ \\
\hline Used by third party & $71 \%$ \\
\hline Has remarkable feature & $34 \%$ \\
\hline Large or very large trees & $27 \%$ \\
\hline Family management & $90 \%$ \\
\hline No wood sold & $76 \%$ \\
\hline Firewood production & $62 \%$ \\
\hline In a protected area (not PNR) & $2 \%$ \\
\hline Associated loan & $2 \%$ \\
\hline & \\
\hline Mostly inherited & $75 \%$ \\
\hline
\end{tabular}

Regarding social interactions, $32 \%$ consider that networking is useful to acquire professional competences and $30 \%$ to acquire professional contacts. Regarding management, $67 \%$ consider that climate change is a serious 
environmental threat (used to measure the degree of awareness of environmental issues) and $24 \%$ consider that abandonment is a good ecological management.

Exogeneity of the variables of Table (3) refers to the decision of adoption of programs; although it is difficult to reject the idea that there may be some common components between adoption decision and some of the variables of Table 3, they are deemed negligible.

Characteristics of the area and of the programs certainly play a role on adoption. However, they are independent of the owners' individual characteristics and of the social networks in which they participate; they are also fairly uniform across the Parc. Therefore, their absence should not affect the results in significant ways.

\section{Models and Econometric Results}

Bénabou and Tirole (2006) [1] present their model in a time-like context: when economic incentives are introduced, they may crowd-out social motives. From an empirical point of view, individual time-series data of incentive changes are very difficult to create or find as that would require a panel purposefully designed. Experimental data might be an alternative, but it is also possible to interpret a cross-section in a long-term sense. Individual characteristics in the sample allow for a control; that is, each respondent is seen as an experimental unit that has undergone a number of treatments. These are his/her individual characteristics and those of his/her property. Econometric estimation sorts out the effect of each of those "treatments" so that each individual can be examined "other things equal", that is, as if they were identical experimental units. More intuitively, the econometric model uses the stated motives for each program and infer, for each respondent, a probability of adoption. When two motives are evoked at the same time, elicitation of a crowding-out effect boils down to estimating whether the probability of adoption is smaller than it would be if the two motives simply added up.

\subsection{Economic Model}

As indicated, the Bénabou and Tirole (2006) [1] model presents the possibility of crowding-out between monetary and social incentives; that means that if a forest owner is socially motivated, introducing monetary benefits (and thus possibly motives) may reduce her interest in the program, for a range of benefits. Bénabou and Tirole consider that this is due to the fact that the social motive is in fact not fully genuine but caused by a desire for 
a good reputation, and that for the prosocial behavior to have its full reputational utility (for the respondent), it must also appear disinterested. When the respondent does not appear disinterested, she does not enjoy such a large reputational boost as if she did. For Bénabou and Tirole, this appears to be a maintained hypothesis, as there is no formal empirical basis to assert its occurrence in a population. This hypothesis can be tested using the present sample. It will turn out not to be verified.

Formally, Bénabou-Tirole's equations (1), (2) and (3), in [2], can be summarized by writing the individual utility of an effort $a$ (discrete or continuous) of participation to the public good, that is adoption of a program, ${ }^{5}$ as

$$
\left(v_{a}+v_{y} y\right) a+x\left(\gamma_{a}-\gamma_{y}\right)-C(a)
$$

where $v_{a}$ and $v_{y}$ are the owner's intrinsic motive ("valuation", utility) from participating in the program (the "public good" incentive of Bénabou and Tirole ${ }^{6}$ ) and extrinsic economic motive ("valuation" of money), respectively; $x$ is the visibility of the behavior - that is, how much of the owner's program adoption can be "seen" by her social network or others; $\gamma_{a}$ is the utility derived from having others observe the adoption and $\gamma_{y}$ is the disutility from having others observe the monetary reward $y$ derived from the adoption. $\gamma_{y}$ appears with a negative sign to underline that agents would prefer to appear disinterested, so that the social incentive is $x\left(\gamma_{a}-\gamma_{y}\right)$ (a "reputational" motive for Bénabou and Tirole). $C(a)$ is the cost of effort $a$, in term of disutility. The model assumes such functional form and does not test it, but the scope of the model is not empirical.

In the case of forest owners, utility is not observed, but only whether the owner adopts any particular program, that is, adding an error term $\varepsilon$ to Equation 1:

$$
\begin{array}{ll}
\text { adopt if } & \left(v_{a}+v_{y} y\right) a+x\left(\gamma_{a}-\gamma_{y}\right)-C(a)>\varepsilon \\
\text { notadopt } & \text { else }
\end{array}
$$

None of these quantities, $a, v_{a}, v_{y}, x, \gamma_{a}, \gamma_{y}, y$ or $C(\cdot)$, can be observed or inferred easily. It might be considered that $y$ (monetary reward) or $x$ (visibility of the monetary incentive) are publicly known, but it is apparent from the survey results that owners' subjective views of the monetary return of any particular program are highly variable, especially for non-adopters who sometimes hold erroneous beliefs on programs. The effort $a$ is not observable as adoption depends on several hard-to-observe factors, as indicated earlier.

\footnotetext{
${ }^{5}$ Tirole (2009) [16] suggests to normalize the effort $a$ to 1 (participate) or 0 (does not), but in an empirical context, the efforts of different persons might differ, so that normalization is not feasible.

${ }^{6}$ As noted earlier, such "public good" dimension is ambiguous as different respondent tend to have a different opinions of what the public good is.
} 
However, the significance of the different motives $v_{a}, v_{y}, \gamma_{a}$, and of the crowding-out effect, $\gamma_{y}$, in the adoption decision may be tested in a discrete choice model. The social incentive $\gamma_{a}$ exists only if the social motive has a significant effect on the probability of adoption; similarly for the economic incentive $v_{y}$ with the economic motive, and the "public good" incentive $v_{a}$ and the ethical motive. Crowding-out exists only if the impact of the social motive, on the probability of adoption, is reduced by the economic motive. Such a reduction can be tested in a discrete choice model by the sign of the coefficient of the cross-product of the two motives: the presence of the two motives together (and hence of the two incentives, at least subjectively for the respondent) leads to a lower probability of adoption than the added effects of the two motives. This opens the way to small empirical generalizations of the crowding-out effect to the other pairs of motives : economic-ethical, social-ethical.

\subsection{Discrete Choices Models}

The outcome of interest are discrete, without any particular order between the programs. Non-adoption of all the programs is complementary to adoption of at least one program, but not to the adoption of any particular program, so that the sets of significant regressors need not mimic each others. Two models may be estimated. The first is a probit model on the probability of adopting "no program". This is expressed formally in the classical probit as:

$$
\operatorname{Pr}\{\text { Noadoption }\}=\int_{-\infty}^{x \beta} \phi(t) d t
$$

where $\phi$ is the standard normal density, $x$ is a vector of explanatory variables including the motives, and $\beta$ is the vector of unknown coefficients of these explanatory variables, reflecting their quantitative impacts on the probability of adoption.

Probit models could also be estimated for each of the three programs (ProSilva, Conventional Management, Environmental NGO), but that would assume a zero correlation between the three. Since it appears that virtually no respondent is involved in more than one program, there is a strong negative (unconditional) correlation between the adoption decisions, which may remain even when conditioned on regressors. The second model of interest is then a multivariate probit, ${ }^{7}$ which is based on a multi-integral extension of the probit probability 3 , see e.g. Cameron and Trivedi (2005) [3] p.517.

Estimation is classically by maximum likelihood for probit, and maximum simulated likelihood for the multi-

\footnotetext{
${ }^{7}$ Sometimes referred to as "Multinomial probit", see Cameron and Trivedi (2005) [3]. The well-known multivariate (or multinomial) logit is also ruled out as this model imposes a fixed correlation between decisions.
} 
variate probit, see e.g. Cameron and Trivedi (2005) chapter 12 [3]. ${ }^{8}$ The methodology is encompassing, starting from a large set of regressors and gradually reducing to avoid multicollinearity issues and test whether groups of dropped regressors are not jointly significant. Polynomial of the regressors have not been used, except for the motives products, as that would have entailed too large a regressors set and there was no a priori theory for non-linear effects of such variables.

The motives are modeled in Probability (3), or in its multivariate equivalent, by a set of three dichotomous variables (some respondents indicate no motive for adoption so that all three dichotomous variables may be zero simultaneously). Interaction between motives is modeled by the three cross-products of the motives, see Table (4). More precisely, consider two motives, A and B; each dichotomous variable reflects, through its coefficient, the direct effect of the motive on the probability. Such direct effect is due, for a particular respondent, both to the presence of the motive in her "psychological" profile, e.g. whether the respondent cares about an economic incentive, and to the perceived presence of the corresponding (extrinsic) incentive, e.g. whether the respondent believes an economic benefit is associated to a given program. The cross-product of the two dichotomous variables reflects the joint effect of the two motives on the probability. If its sign is negative, the joint effect is a crowding-out: the combined presence of the two motives is less than the sum of the effect of the two separate motives. If the sign is positive, the two effect are complementary and their joint presence reinforces each other: the combination of the two motives leads to more than the sum of the parts.

The econometric model does not restrict a priori the sign of the coefficients of such cross-products, or their statistical significance; so that estimation is really a test of the Bénabou and Tirole (2006) [1] theory: if the sign of the coefficient of the social-economic cross-product turns out statistically non-significant, or significantly larger than zero, than the present survey turns out an evidence against the theory. Conversely, if it turns out significantly smaller than zero, then the present paper offers one piece of evidence in favor of the theory. The other two cross-products, economic-ethical and social-ethical, do not belong to the Bénabou and Tirole (2006) [1] theory, and so their signs cannot be interpreted as a test of the theory.

\subsection{Results}

Table (4) presents the results of the estimation the probit model (3) on no adoption, and its corresponding multivariate equivalent for the three programs (ProSilva, Conventional Management, Environmental NGO).

\footnotetext{
${ }^{8}$ The Stata Package has been used. For multivariate probit, the user-developed mvprobit package has been used, see Cappellari and Jenkins (2003) [4].
} 
Table 4: Probability to adopt any one of the three programs - or nothing $-\mathrm{n}=600$

\begin{tabular}{|c|c|c|c|c|c|c|c|c|}
\hline & \multicolumn{6}{|c|}{ Multivariate Probit } & \multicolumn{2}{|c|}{ Probit } \\
\hline & \multicolumn{2}{|c|}{$\operatorname{Pr}\{$ ProSilva $\}$} & \multicolumn{2}{|c|}{$\operatorname{Pr}\{E n v \cdot N G O\}$} & \multicolumn{2}{|c|}{$\operatorname{Pr}\{C \cdot M\}}$. & \multicolumn{2}{|c|}{$\operatorname{Pr}\{$ nothing $\}$} \\
\hline & Coef. & $\mathrm{p}$ & Coef. & $\mathrm{p}$ & Coef. & $\mathrm{p}$ & Coef. & $\mathrm{p}$ \\
\hline \multicolumn{9}{|l|}{ Forest property } \\
\hline Property surface & + & $* * *$ & 0 & & + & $* * *$ & - & $* * *$ \\
\hline Large or very large trees & + & $\mathrm{o}$ & 0 & & 0 & & - & $*$ \\
\hline Mostly inherited & 0 & & - & $*$ & 0 & & 0 & $\geq .1$ \\
\hline Managed by $3^{\text {rd }}$ party & + & $* *$ & 0 & & + & $* * *$ & - & $* * *$ \\
\hline Firewood production & 0 & & 0 & & - & $*$ & 0 & $\geq .1$ \\
\hline In a protected area (not PNR) & 0 & & + & $*$ & 0 & & 0 & $\geq .4$ \\
\hline \multicolumn{9}{|l|}{ Owner } \\
\hline Age & 0 & & + & $* *$ & + & $\mathbf{o}$ & - & $* * *$ \\
\hline Education & 0 & & + & $* *$ & 0 & & - & o \\
\hline Gender & 0 & & - & $*$ & 0 & & 0 & $\geq .4$ \\
\hline In non-professional association & 0 & & + & $*$ & + & $*$ & - & o \\
\hline "network useful for prof. competences" & + & $* *$ & 0 & & 0 & & 0 & $\geq .1$ \\
\hline "network useful for prof. contacts" & 0 & & + & $*$ & + & $*$ & 0 & $\geq .1$ \\
\hline "abandonment not good ecol. manag." & + & $*$ & 0 & & 0 & & - & $*$ \\
\hline Has own environmental actions & \multicolumn{6}{|c|}{ Not significant at $>20 \%$} & - & $*$ \\
\hline Will bequest forest & + & $*$ & 0 & & 0 & & 0 & $\geq .4$ \\
\hline Visits property often & 0 & & + & $*$ & + & $*$ & - & $*$ \\
\hline \multicolumn{9}{|l|}{ Motivation } \\
\hline Economic & + & $* * *$ & + & $*$ & + & $* * *$ & - & $* * *$ \\
\hline Ethical & 0 & & + & $* *$ & + & $*$ & 0 & \\
\hline Social & + & $* * *$ & + & $* * *$ & + & $* * *$ & - & $* * *$ \\
\hline Economic $\times$ Social & 0 & & \multirow{3}{*}{\multicolumn{2}{|c|}{ too few obs. }} & 0 & & 0 & \\
\hline Economic $\times$ Ethical: crowding-out & - & $* *$ & & & - & $* *$ & + & $* *$ \\
\hline Social $\times$ Ethical & 0 & & & & 0 & & 0 & \\
\hline Information & 0 & & 0 & & + & $* *$ & - & 0 \\
\hline
\end{tabular}

Significance levels p : ${ }^{\circ} 10 \% ; * 5 \% ; * * 1 \% ; * * * 0.1 \%$ - C.M. Conventional Management

There is a significant crowding-out between the economic and ethical motives, but not between the economic and social motives. The Bénabou and Tirole (2006) [1] model suggests only the latter and not the former. The crowding-out effect can only be shown for the Prosilva and for the Conventional management programs, as there were too few observations for which both motives were evoked for the Environmental NGO program. The ethical motive, in the context of the present survey, refers to feelings of attachment to the forest and concerns about the mastery of own practices. This crowding-out effect is then likely driven by a feeling of incompatibility between economic incentives and such attachment or mastery, possibly associated with the selling of a part of one's control over one's property.

As indicated, unconditionally, adoptions of the programs are strongly negatively correlated to each other, as evidenced by the fact that nearly no respondent has adopted more than one program. In the Multivariate probit 
model of Table (4), the conditional (residual) correlation between adoption decisions turns out to be not significantly different from zero for the correlation between ProSilva and Environmental NGO, significantly positive between the two management programs (ProSilva and conventional) and significantly negative between Conventional management and Environmental NGO. Therefore, once conditioned on the individual characteristics and motives, and the forest characteristics, the correlations show a certain antagonism between environmental goals and conventional management goals, but that is not the case with ProSilva. Globally, the hypothesis that the three correlation coefficients are jointly zero can be rejected at about the $1 \%$ confidence level.

Finally, Table (5) presents the variables that turned out non-significant for the same models. One of the unexpected results is that none of the spatial regressors is significant.

Table 5: Regressors that can safely be said not to impact adoption $-\mathrm{n}=600$

\begin{tabular}{|c|c|c|c|c|}
\hline \multirow{2}{*}{ p-values } & \multicolumn{3}{|c|}{ Multivariate Probit } & Probit \\
\hline & $\operatorname{Pr}\{$ ProSilva $\}$ & $\operatorname{Pr}\{E n v \cdot N G O\}$ & $\operatorname{Pr}\{C \cdot M\}$. & $\operatorname{Pr}\{$ nothing $\}$ \\
\hline \multicolumn{5}{|l|}{ Forest property } \\
\hline Time since last operation & \multicolumn{3}{|c|}{$\geq .1$} & $\geq .1$ \\
\hline "is not managed" & \multicolumn{3}{|c|}{$\geq .4$} & $\geq .4$ \\
\hline No wood sold & \multicolumn{3}{|c|}{$\geq .4$} & $\geq .4$ \\
\hline Has remarkable feature & \multicolumn{3}{|c|}{$\geq .4$} & $\geq .4$ \\
\hline Used by third party & \multicolumn{3}{|c|}{$\geq .2$} & $\geq .4$ \\
\hline \multicolumn{5}{|l|}{ Owner } \\
\hline Forest income negligible & \multicolumn{3}{|c|}{$\geq .4$} & $\geq .4$ \\
\hline Hunts & \multicolumn{3}{|c|}{$\geq .1$} & $\geq .4$ \\
\hline Climate change is serious threat & \multicolumn{3}{|c|}{$\geq .2$} & $\geq .4$ \\
\hline \multicolumn{5}{|l|}{ Spatial } \\
\hline Lives close to oldest parcel & \multicolumn{3}{|c|}{$\geq .4$} & $\geq .4$ \\
\hline Knows neighboring properties and owners & \multicolumn{3}{|c|}{$\geq .1$} & $\geq .2$ \\
\hline Knows neighboring properties, not owners & \multicolumn{3}{|c|}{$\geq .2$} & $\geq .4$ \\
\hline
\end{tabular}

\section{Conclusions}

There are fewer program adopters than expected, about $22 \%$ of the sample. Out of 627 observations, only two owners adopt two programs, 139 adopt one program. The probabilities of adopting any of the three programs (ProSilva, Environmental NGO, Conventional management) were estimated using a multivariate probit model to account for the strong negative correlation between adoption decisions. The owners' and properties' characteristics have the expected effects, in particular, programs are adopted primarily on larger properties. Unsurprisingly, economic incentives (extrinsic motivations) have a clear positive effect on the probability to adopt 
a management program (conventional or ProSilva), but not to adhere to an environmental NGO. Social motivations significantly impact adoption of all three types of program positively, while ethical motivations have a clear positive effect on adhesion to an environmental NGO. Non-adoption primarily depends on economic and social motives, not on ethical ones.

There appears to be a significant crowding-out between economic and ethical motivations, for the adoption of both types of management programs (conventional and ProSilva), so that the probability of adopting such programs will decrease when economic incentive increase over a certain range and ethical motivation remains constant. Similarly, owners are more likely not to adopt a incentivized program if they perceive that their control over their property is lessened (positive and significant sign of the cross-product of the ethical and economic motives in the decision not to adopt any program).

Such conclusions on individual motivations for adopting programs lead to questioning of the use of ecosystem services valuation from a policy point of view. Valuation leads naturally to the idea that forest owner might be financially compensated for these services. Although that is undoubtedly an important motivation following the results presented in the present paper, and therefore, it might be expected that paying for ecosystems services will increase their supply, it remains that these economic incentives crowd-out the ethical motivations. Therefore, it is not immediately clear that because ecosystem services values can be estimated, they should be translated to economic incentives for the supplier of such services. As already seen in several circumstances, e.g. Oliver (2013) [14], such crowding-out might induce a decrease of ecosystem services.

Contrarily to the maintained hypothesis in Bénabou and Tirole (2006) [1], there is no crowding-out between the economic and the social motives. There is also no crowding-out between the ethical and the social motives. Therefore, social motives are in a particular position for being used as leverages of public programs. That would constitute a future research avenue, but one could imagine that programs that enhance the social reward of the forest owners who adopt them might be more economically efficient, that is, lead to more adoption for the same level of public spending - or less public expenses for the same level of adoption. That leads to programs that would allow owners to interact between themselves and with the administration, and thus advocates for a more bottom-up approach. Further, programs, that focus on the social motivations through the use of nudges, see e.g. Oliver (2013) [14], might also achieve the same outcome at a lower cost. The strong negative correlation between adoption decisions lead to recommend avoiding creating new programs and instead modify existing ones. 


\section{References}

[1] Roland Bénabou and Jean Tirole. Incentives and prosocial behavior. American Economic Review, 96(5):1652-1678, September 2006.

[2] Roland J. Bénabou and Jean Tirole. Incentives and prosocial behavior. IZA Discussion Papers 1695, Institute for the Study of Labor (IZA), 2005.

[3] A. Colin Cameron and Pravin K. Trivedi. Microeconometrics Methods and Applications. Cambridge University Press, 2005.

[4] Lorenzo Cappellari, Stephen P Jenkins, et al. Multivariate probit regression using simulated maximum likelihood. The Stata Journal, 3(3):278-294, 2003.

[5] Jeffrey Carpenter and Caitlin Knowles Myers. Why volunteer? evidence on the role of altruism, image, and incentives. Journal of Public Economics, 94(11-12):911 - 920, 2010.

[6] Ophélie Darses, Serge Garcia, and Anne Stenger. Drivers of cooperation for environmental goods: Evidence from a national survey on french private forest owners. 5eme Journées de recherches en sciences sociales INRA - SFER - CIRAD, 2011.

[7] Philippe Delacote, Serge Garcia, Anne Stenger, and Gengyang Tu. Private forest owners' participation behavior related to an incentive conservation program: a case study of natura 2000 contracts in france. Technical report, Laboratoire d'Economie Forestiere, AgroParisTech-INRA, 2014.

[8] Richard B Freeman. Working for nothing: The supply of volunteer labor. Technical report, National bureau of economic research, 1996.

[9] Bruno S. Frey and Felix Oberholzer-Gee. The cost of price incentives: An empirical analysis of motivation crowding- out. American Economic Review, 87(4):746-755, 1997.

[10] U. Gneezy and A. Rustichini. A fine is a price. Journal of Legal Studies, 29:1-17, 2000.

[11] Heimo Karppinen et al. Values and objectives of non-industrial private forest owners in finland. Silva fennica, 32:43-59, 1998.

[12] Angelina Kendra and R Bruce Hull. Motivations and behaviors of new forest owners in virginia. Forest Science, 51(2):142-154, 2005. 
[13] Karine Nyborg and Mari Rege. Does public policy crowd out private contributions to public goods? Public Choice, 115:397-418, 2003.

[14] Adam Oliver. Behavioural public policy. Cambridge University Press, 2013.

[15] Richard M Ryan and Edward L Deci. Intrinsic and extrinsic motivations: Classic definitions and new directions. Contemporary educational psychology, 25(1):54-67, 2000.

[16] Jean Tirole. Motivation intrinsèque, incitations et normes sociales. Revue économique, 60(3):577-589, 2009.

[17] Stéphane Weiss. Le regroupement des petits propriétaires forestiers en vue d'une gestion concertée. Revue Forestière Française, 55(4-2003):358-366, 2003. 